\title{
Direitos políticos e representação no Brasil Republicano (1891-1934)
}

\author{
Cláudia M. R. Viscardi ${ }^{*}$
}

Resumo: Trata-se de uma discussão acerca de dois tipos de direitos políticos o de voto e o de representação parlamentar - ao longo das primeiras décadas republicanas brasileiras (1891-1934). Com base no estudo das leis eleitorais, das primeiras duas constituições republicanas, da análise dos anais parlamentares e de dicionários de época, entre outras fontes, pretende-se discutir o tema geral da cidadania política, comparando dois períodos distintos da república brasileira. Destaca-se para o segundo período a criação da representação corporativa, o que nos conduziu a refletir sobre o seu papel na ampliação da cidadania política. $O$ artigo envolve também um diálogo com as reflexões em torno do conceito de cidadania e de seus usos para a análise da realidade brasileira.

Palavras-chave: cidadania; corporativismo; voto.

Abstract: This paper deals about two types of political rights - the right to vote and the right of parliamentary representation - during the first republican decades in Brazil (1889-1937). Based on the study of the electoral laws, the first two Republican Constitutions, the analysis of parliamentary annals and contemporary dictionaries, among other sources, we intend to discuss the political citizenship in general, as well as to compare the political participation during the two distinct periods of the Brazilian Republic. It is important to stress that in the second period (1930-1937) was created the corporative representation, which led us to reflect on its role in broadening political citizenship. The article also involves a dialogue with the reflections around the concept of citizenship and its applications over Brazilian reality.

Keywords: citizenship; corporatism; vote.

O presente artigo tem como fim propor uma reflexão acerca dos direitos da cidadania política ao longo de dois períodos, da primeira e da segunda república (1889-1937), tendo como eixos básicos as duas constituições em vigor no período, a de 1891 e a de 1934 .

Dada a amplitude dos recortes, cronológico e temático, para o espaço de um artigo, escolhemos analisar apenas dois direitos políticos, inter-relacionados em sua essência: o direito de escolha dos governantes (o direito de voto) e o de ter os seus interesses representados no Parlamento, com ênfase sobre a representação

\footnotetext{
* Professora do Programa de Pós-Graduação em História da Universidade Federal de Juiz de Fora. Pesquisadora do CNPq. O texto é resultado de pesquisa financiada pela FAPEMIG e pelo CNPq.
} 
corporativa. Reconhecemos que tais abordagens estão longe de corresponder às inúmeras possibilidades de análise do tema, mas preferimos recortá-lo a ter que tratá-lo de forma generalizante, sem levar em conta toda a sua complexidade.

Pretendemos, pois, analisar a normatização jurídica dos processos eleitorais republicanos e das alternativas de representação institucional de interesses neles condensadas, buscando relacioná-los a dois contextos distintos, o da primeira e o da segunda república, de forma continuada, ou seja, sem ver a Revolução de 30 como um divisor de águas. A transversalidade da cidadania política entre as duas repúblicas, cujas distinções são mais aparentes que reais, é uma das abordagens que se pretende desvelar ao longo do texto.

A conferência de T. H. Marshall, proferida em 1949 e no ano seguinte publicada no livro intitulado "Cidadania, classe social e status", 1 tornou-se clássica, tanto pela sua capacidade de síntese do fenômeno da cidadania quanto pelas controvérsias que gerou entre os pares. A divisão tripartite dos direitos e seu ordenamento cronológico e progressivo facilitaram a compreensão do conceito. O século XVIII teria sido caracterizado pela introdução e consolidação dos direitos civis resultantes das convulsões revolucionárias do período anterior na Inglaterra; o século XIX teria sido o período da expansão dos direitos políticos por meio do fortalecimento dos parlamentos e, por conseguinte, das eleições, dos partidos e do voto; e o século XX teria sido marcado pela expansão dos direitos sociais, motivada principalmente pela crise de 1929, e pelas duas guerras mundiais. O advento do Welfare State constituiu-se em sua mais visível expressão.

Em que pesem a criatividade e profundidade das análises, a tese de Marshall realçou o caráter progressivo das conquistas, como se a cidadania fosse o resultado de um acúmulo de direitos em expansão ao longo do tempo. Em seu bojo prevalece a ideia de que uma vez conquistados, os direitos não poderiam ser mais retirados, ou que a trajetória da História seria sempre ascendente. Ademais, a pressuposição que se deixa antever é que o desenrolar dos direitos na Inglaterra funcionaria como um "tipo ideal" a servir de paradigma para outras nações, dentro ou fora do continente europeu. Resta claro que experiências que não tivessem trilhado esse caminho seriam vistas como desviantes ou incompletas.

Como já se pode antecipar, o caso brasileiro foi, em sua maior parte, interpretado como desviante, uma vez que o estabelecimento dos direitos de cidadania foi tardio, insuficiente e instável. ${ }^{2}$ Não obstante a pertinência de tais avaliações acerca do quadro nacional, o caso inglês foi muito mais uma exceção do que regra, pois raros foram os países que implantaram e mantiveram os direitos conquistados ao longo do tempo. O Brasil não seria uma exceção, mas antes a regra.

Inúmeras outras críticas podem ser feitas ao trabalho de Marshall, ${ }^{3}$ mas, mesmo assim, ele se tornou uma referência em várias abordagens sobre o

1 MARSHALL, T. H. Cidadania, classe social e status. Rio de Janeiro: Zahar, 1967.

2 Esse é o caso das abordagens de SANTOS, Wanderley G. Cidadania e justiça. Rio de Janeiro: Campus, 1979; QUIRINO, Célia; MONTES, Maria L. Constituições brasileiras e cidadania. São Paulo: Ática, 1987; CARVALHO, José Murilo de. A Cidadania no Brasil: o longo caminho. $2^{\text {a }}$ ed. Rio de Janeiro: Civilização Brasileira, 2002; PRADO, Maria E. Memorial das Desigualdades: os impasses da cidadania no Brasil, 1870-1902. Rio de Janeiro: Revan, 2005, entre outros.

3 Entre elas destacamos a linearidade de sua abordagem, a omissão dos conflitos étnico-raciais e de gênero, a subestimação das lutas classistas, a ausência de uma análise geopolítica, entre outros problemas. A esse respeito, ver: GIDDENS, Anthony. "Class division, class conflict and citizenship rights". In:

Profiles and critiques in social theory. London: Macmillan, 1982, p. 171-173 e p. 176; MANN, M. "Ruling class strategies and citizenship". Sociology, v. 21, n. 3, p. 339-359, 1987. TURNER, Bryan. "Outline of a theory of citizenship". Sociology, v. 24, n. 2, p. 33-61, 1990. 
estudo da cidadania no Brasil e fora dele. Não nos cabe aprofundar sobre elas, dados os fins do presente texto. Apenas queremos destacar que evitaremos ver a expansão dos direitos de forma progressiva, mas sim como resultado de avanços e recuos, vitórias e derrotas dos diferentes grupos de interesse. E nem veremos direitos conquistados como etapas garantidas, que uma vez vencidas, não possam voltar atrás. Temos acompanhado ao longo de nossa história o fluxo e o refluxo de direitos, que podem ser ampliados ou reduzidos, em meio à volatilidade dos governos. Ademais, embora levemos em conta o usufruto dos direitos políticos por parte de outras nações, não tomaremos os casos mais paradigmáticos como referências a partir das quais nossa cidadania seria avaliada como mais ou menos incompleta. Outrossim, cabe ressaltar, como o faz Sérgio Tavolaro, ${ }^{4}$ a ocorrência no Brasil de "modernidades múltiplas", as quais se constituem em configurações variadas de direitos em contextos marcados por variações e assimetrias regionais e temporais, o que nos leva a evitar generalizações.

Charles Tilly 5 afirma que uma experiência cidadã forte pressupõe a existência de uma hierarquia de servidores púbicos que atue do centro para as periferias e delas de volta ao centro, sendo o Estado um importante ator social no processo de expansão da cidadania. No caso específico do Brasil, o protagonismo do Estado por meio de sua burocracia na promoção e ampliação dos direitos políticos deve ser levado em conta, se quisermos compreender melhor nosso processo de expansão dos direitos.

É dessa forma que pretendemos abordar o tema dos direitos políticos e das representações na primeira e segunda república brasileiras. Para tal, estaremos igualmente atentos à gramática política compartilhada pelos principais atores e ao repertório de possibilidades disponíveis para os atores que se mobilizaram a favor ou contra a expansão de alguns direitos, sendo eles entes públicos ou privados.

Para a construção deste texto nos valemos de um conjunto variado de fontes. Não só os textos constitucionais foram analisados, bem como boa parte da legislação infraconstitucional. Foram consultados os Anais do Parlamento, manifestos, bem como as leis eleitorais. Para a compreensão do "mapa semântico" disponível aos grupos sociais, o uso dos dicionários de época foi de grande valia. O diálogo com a vasta historiografia sobre o tema será apresentado ao longo do texto. Ele também incorporou as análises dos contemporâneos, referenciados ao final como fontes primárias bibliográficas.

\section{Os processos eleitorais republicanos e a experiência da cidadania política no Brasil}

O fato de a República ter sido proclamada por meio de um golpe civil-militar não desmerece o forte movimento que a antecedeu em prol da mudança do regime ocorrido em várias províncias brasileiras, embora concentrado nos centros urbanos mais dinâmicos. O republicanismo das ruas, cujos principais protagonistas eram

4 TAVOLARO, Sérgio B. "Quando discursos e oportunidades políticas se encontram. Para repensar a sociologia política da cidadania moderna”. Revista Novos estudos CEBRAP, n. 81, São Paulo, 2008. Disponível em: http://www.scielo.br/scielo.php?pid=S0101-33002008000200010\&script=sci_arttext RESP. Acesso em 21 de abril de 2017.

5 TILLY, Charles. Citizenship, Identity and Social History. Cambridge: Cambridge University Press, 1996, p. 228. 
setores emergentes que se encontravam à margem do poder no regime imperial, era portador e divulgador de uma nova cultura política. Por meio dela, valores como o da liberdade, meritocracia, descentralização e da soberania popular eram divulgados sob a forma de projetos alternativos ao regime em curso. Estabelecia-se um novo horizonte de expectativas para os contemporâneos, em que pese o movimento ter sido restrito às elites econômicas e políticas letradas e apartadas da maioria da população brasileira. ${ }^{6}$

Para um melhor entendimento das propostas dos republicanos, que acabaram por definir a normatização dos direitos políticos após a proclamação, a análise do vocabulário compartilhado pelos contemporâneos é muito valiosa. Nem sempre os dicionários nos garantem que um conceito uma vez publicado expresse uma relação única entre o significante e o seu significado. Mas ao ser formalizado em "língua culta", ele passa a ser referência, tornando-se usual. Dessa forma, os dicionários são capazes de nos dar acesso à gramática política de um período. Para analisar os direitos políticos, escolhemos três conceitos: o de povo, o de democracia e o de cidadania.

Em relação ao primeiro, no dicionário de Moraes e Silva, de 1831, pode ser encontrada a seguinte definição de povo: "Vulgo é propriamente o comum do povo (...) que, ou por sua ignorância, ou por seus baixos sentimentos e ações pertencem ao comum da gente, ao que é mais ordinário, ao maior número". Já no dicionário de Vieira, de 1873, se lia: "Plebe é a gente comum e baixa do povo, o que não é nobre".?

Como se pode inferir, a participação do povo nos processos decisórios nos oitocentos estava limitada à noção de povo como vulgo, ou seja, incapaz de ter uma atuação qualificada na política. Portanto, antes de "temer" o povo, as elites republicanas o desqualificavam e o mantiveram apartado dos canais deliberativos. O resultado foi dar continuidade à exclusão da maioria da população do direito de voto, limitando-o à parcela mínima da população.

A expressão "soberania popular" encontrada nos manifestos republicanos era sinônima de democracia, conceito veiculado com menos frequência nos documentos de época. No dicionário de Almeida, que circulava entre Rio e Lisboa ao final do século XIX, a palavra democracia significava uma prática em que os privilégios de sangue seriam substituídos pelos de mérito, o que propiciaria a igualdade de oportunidade a todos. ${ }^{8}$ Tal definição vinha ao encontro de uma das principais bandeiras do republicanismo oitocentista: o fim dos privilégios decorrentes dos títulos nobiliárquicos. Nota-se que "todos" não se referia a uma categoria geral e inclusiva, mas apenas à parte da população que compunha a "polis", ou seja, o pequeno grupo que detinha os direitos políticos.

Em 1831, Moraes e Silva referia-se aos cidadãos - a palavra cidadania ainda não existia - como “homens bons dotados de privilégios". Já em 1889, em outra edição do mesmo dicionário, cidadãos eram os indivíduos que gozassem de direitos

6 Destacamos algumas abordagens mais recentes sobre o tema: ALONSO, Ângela. Ideias em movimento: a geração de 1870 na crise do Brasil-Império. Rio de Janeiro: Paz e Terra, 2002; MELLO, Maria T. C. de. A República Consentida: Cultura Democrática e Científica no Final do Império. Rio de Janeiro: FGV, EDUR, 2007.

7 MORAES E SILVA, Antonio de. Dicionário da língua portuguesa. Lisboa: Tipografia Lacerdina, 1813 e 1831, tomo II, p. 499, grifos nossos. VIEIRA, Frei Domingos. Grande Diccionario Portuguez ou Tesouro da Língua Portuguesa. Casa dos editores Ernesto Chardrom e Bartholomeu H. de Moraes, Rio de Janeiro/Pará, 18721874, tomo IV, p. 874-876.

8 ALMEIDA, Francisco de. Novo Dicionário Universal Português. Lisboa: Tavares Cardoso e Irmão, 1891, p. 602. 
civis e políticos em um estado livre, em contraposição a um fidalgo ou a um nobre. ${ }^{9}$ Ao compararmos as duas definições, separadas por um intervalo de quase 60 anos, percebemos que o conceito de cidadania no alvorecer da República deixara de estar relacionado a privilégios, passando a ser visto como um conjunto de direitos. Tal mudança discursiva relacionava-se à difusão dos valores republicanos e de seus vínculos tardios com os ideais iluministas, por meio de um novo modelo, o da Terceira República Francesa.

Com base nesse modelo de cidadania e no conceito de povo e soberania que possuíam, foram estabelecidos os direitos ao voto e à representação política. Explicam-se, dessa forma, os seus limites.

\section{Quem votava}

Os republicanos recém empossados, por meio de seu primeiro decreto eleitoral, preocuparam-se em alterar a Lei Saraiva, em vigor desde 1881, ao extinguir o voto censitário, estabelecer eleições diretas em todos os níveis e ao reduzir o requisito etário de 25 para 21 anos de idade. Tais medidas ampliariam o contingente de eleitores, mas a manutenção da proibição do voto aos analfabetos, às mulheres e a previsão do voto facultativo manteriam baixos os indicadores de participação popular nos processos eleitorais. Entre 1894 (primeira eleição direta para a Presidência da República) e 1945 (período de democratização), o percentual de eleitores variou em média entre $2 \%$ e $10 \%$ respectivamente, segundo dados de Jairo Nicolau. ${ }^{10}$ Dainis Karepovs afirma que em 1920 apenas 7,15\% da população do país tinha direito a voto, tendo em vista essa multidão de excluídos. ${ }^{11}$

Tal situação não se diferenciava muito dos demais países da América Latina, a exemplo do Uruguai, Chile e Argentina, nem de alguns países europeus, como a Itália, Portugal, Noruega, entre outros. Exceções claras eram a França e os Estados Unidos, que detinham um número maior de eleitores.

Para Hilda Sabato, ${ }^{12}$ a população nem sempre entendia que votar era um caminho desejável de participação política. As elites políticas frequentemente reclamavam da indiferença da população ou da falta de espírito cívico. Segundo a autora, na maioria das vezes, as máquinas políticas se esforçavam menos por controlar votos e mais por fazer as pessoas votarem.

Um dos fatores responsáveis pelo baixo coeficiente eleitoral - para além do voto facultativo e do voto literário - era a não previsão do voto feminino. O debate acerca do direito de voto das mulheres foi intenso na Constituinte de 1891. Havia inúmeros defensores, tanto na comissão responsável por elaborar o anteprojeto quanto no plenário. Assinaram a emenda propositiva 28 constituintes, liderados por Saldanha Marinho, que, no entanto, não foi aprovada.

9 MORAES E SILVA, Antonio de. Dicionário da língua portuguesa. Nova edição revista e melhorada. Rio de Janeiro e Lisboa: Empresa Literária Fluminense, 1831 e 1889, p. 464.

10 NICOLAU, Jairo. “A participação eleitoral: evidências sobre o caso brasileiro". Paper apresentado no VIII Congresso Luso-Brasileiro de Ciências Sociais. Coimbra, 2004, p. 2, 4 e 8.

11 KAREPOVS, Dainis. A classe operária vai ao Parlamento: o bloco operário e camponês do Brasil (1924-1930). São Paulo: Alameda, 2006, p. 15.

12 SABATO, Hilda. "On political citizenship in Nineteenth-Century Latin America". The American Historical Review, v. 106, n. 4, October, 2001, p. 1303. 
A propositiva era inovadora, uma vez que, na ocasião, em muito poucos países vigorava o direito da mulher ao voto..$^{13}$ De certa forma, em sentido estrito, as mulheres já eram consideradas cidadãs no Brasil, pois eram capazes de conferir cidadania a um estrangeiro pelo matrimônio. No entanto, o Artigo 70, que previa quais seriam os eleitores, deixava a questão em aberto, ao definir que eram eles os cidadãos maiores de 21 anos, que fossem alfabetizados, sem que as mulheres fossem excluídas ou incluídas.

Em razão dessa "questão em aberto", na década de 1910, alguns deputados tentaram de novo rediscutir o direito ao voto feminino, sem muito êxito. Em 1926, no contexto da reforma constitucional, o Rio Grande do Norte foi o primeiro estado a conferir o direito ao voto pelas mulheres. Nas eleições de 1928 daquele estado, 15 mulheres votaram, embora seus votos não tenham sido apurados. ${ }^{14}$

Foi somente no Código Eleitoral de 1932 que foi previsto o direito das mulheres de votar. $\mathrm{O}$ Artigo $2^{\circ}$ do referido código estabelecia que seriam eleitores os maiores de 21 anos, sem distinção de sexo. Para a Assembleia Constituinte de 1933, uma mulher foi eleita por São Paulo, e a cientista Bertha Lutz, conhecida por sua militância feminista, foi suplente de um deputado eleito pelo Distrito Federal.

Conforme afirmou-se, apesar da inclusão das mulheres, os níveis de participação eleitoral ainda permaneceram muito baixos até que o voto se tornasse obrigatório ou que os analfabetos pudessem votar, o que ocorreu em 1945 e 1988, respectivamente. Embora tenhamos tido alguma ampliação do número de eleitores no período entre as duas constituições, a extensão do direito de voto às mulheres não impactou por demasiado o percentual extremamente baixo de participação eleitoral. Se compararmos o coeficiente eleitoral das eleições de 1930 com as de 1934, veremos que houve uma ampliação de menos de dois pontos percentuais. ${ }^{15}$ Os conceitos de povo, democracia e cidadania já haviam mudado e se aproximado do entendimento que hoje temos deles. Mas as restrições à universalidade do sufrágio permaneceram, com poucas alterações.

\section{O processo eleitoral}

Na ausência de uma Justiça Eleitoral, que só seria criada em 1932, o regime republicano recém implantado atribuiu a responsabilidade sobre a organização das eleições a duas comissões: as distritais e as municipais. Dessa forma, o controle sobre os processos eleitorais ficaria a cargo do Poder Executivo. A criação de distritos eleitorais em substituição às paróquias e comarcas como mecanismos de divisão geográfica das seções foi outra mudança introduzida pela República. Aparentemente inofensiva, ela abandonava os critérios de divisão eminentemente judiciários em prol da obediência à geografia dos municípios. As mesas eleitorais, compostas anteriormente pelos juízes de paz, passaram a ser organizadas por indicação dos presidentes das câmaras municipais. Tanto as eleições como a sua apuração eram feitas no município, sob o controle dos mesmos agentes

13 Destacam-se alguns exemplos: na Nova Zelândia as mulheres passaram a votar em 1893; na Austrália, em 1902; Noruega, em 1913; e na Alemanha e Inglaterra somente em 1918.

14 PORTO, Walter C. O voto no Brasil. $2^{\mathrm{a}}$ ed. Rio de Janeiro: Topbooks, 2002, p. 235.

15 Para os dados das eleições de 1930 (5,7\%) ver: CAVALCANTI, Themistocles B. O voto distrital no Brasil. Rio de Janeiro: FGV, 1975. E para os dados relativos a 1934 (7\%) ver: NICOLAU, Jairo. Eleições no Brasil: do Império aos dias atuais. Rio de Janeiro: Zahar, 2012, p. 80. 
responsáveis pelo processo de alistamento e redação das atas eleitorais. As atas municipais, nas eleições majoritárias, eram remetidas às capitais dos estados, nas quais uma junta eleitoral era responsável pela contabilidade final dos votos, sob forte intervenção dos governadores.

Cabe destacar que, na maior parte do período em tela, predominou o voto distrital misto em lista fechada, condição alterada em 1932, conforme se verá. No Parlamento, um último escrutínio era realizado, o processo de verificação de poderes, por meio do qual diplomava-se os eleitos com base no número de cadeiras correspondentes a cada bancada estadual. A metáfora do "filtro" utilizada largamente pela imprensa do período é perfeita para explicar as diferentes fases do processo eleitoral republicano, no qual o excessivo número de candidatos considerados eleitos era subtraído até que se atingisse a correspondência entre candidatos e vagas disponíveis.

O derradeiro processo de filtragem, pois, se dava por meio da verificação de poderes. Embora pesquisas recentes tenham subestimado o papel da "guilhotina final" sobre a composição das legislaturas, até o advento da Justiça Eleitoral o Parlamento mantinha-se como o órgão responsável final por sua própria renovação. ${ }^{16}$

Ao longo de todo o processo eleitoral eram permitidas contestações. Por meio delas, os candidatos excluídos denunciavam fraudes ou irregularidades e para tal poderiam se fazer representar por meio de advogados especialmente contratados para esse fim. Podiam agregar documentos ao processo de luta pela legitimidade de suas respectivas candidaturas, o que tornava o processo altamente burocratizado e demandava dos envolvidos tempo e expertises diversas. Demorava-se mais na definição dos resultados do que no processo de escolha em si. Toda essa complexidade envolvida na disputa eleitoral extrapolava as eleições propriamente ditas.

Com o passar do tempo, percebe-se uma ampliação progressiva do envolvimento do Judiciário nos processos eleitorais. As leis eleitorais de 1916 (n..$^{\circ} 3.139$ e a de.$^{\circ}$ 3.208), duas das mais importantes da Primeira República, anularam todos os alistamentos anteriores, incumbindo as autoridades judiciárias da missão de requalificar todos os eleitores para as eleições presidenciais que ocorreriam dois anos depois. Por meio delas, a apuração para as eleições majoritárias deixou de ocorrer nas sedes dos distritos e foi centralizada nas capitais dos estados por juntas apuradoras compostas por membros exclusivamente do Judiciário. Tal mudança acabou por fragilizar a "política dos estados", aprovada por iniciativa de Campos Sales em 1900, ao retirar dos executivos estaduais o controle sobre os resultados das urnas. ${ }^{17}$

A ideia de que as eleições eram muito pouco competitivas merece ser questionada. Na maior parte das vezes, tendemos a generalizar para todo o país os processos políticos ocorridos em estados nos quais as oligarquias eram mais

16 Um estudo da década de 1980 fez um levantamento sobre os números de degolas ocorridas durante a Primeira República, chegando a um índice inferior a 11\%. Estudos mais recentes analisaram as inúmeras contestações às decisões das comissões de inquérito e mensuraram os impactos delas na alteração dos resultados. Para o primeiro caso, ver: MAGALHÃES, Maria Carmem C. "O mecanismo das 'comissões verificadoras' de poderes: estabilidade e dominação política, 1894-1930" (Dissertação de mestrado em História, UNB, 1986) e para o segundo, ver: RICCI, Paolo; ZULINI, Jaqueline. “'Beheading”, rule manipulation and fraud: the approval of election results in Brazil, 1894-1930". Journal of Latin American Studies, Cambridge: Cambridge University Press, 2012.

17 VISCARDI, Cláudia M.R. "O Federalismo como experiência: Campos Sales e as tentativas de estabilização da República”. Revista Dados, Rio de Janeiro, v. 59, n. 4, 2016. 
unidas, como foram os casos de Minas Gerais, São Paulo e Rio Grande do Sul. Em estados divididos politicamente, cujo controle derivava de lutas fratricidas entre oligarquias regionais que se opunham, a competição eleitoral processava-se em campo aberto. A fraude e as tentativas de controle do voto do eleitor se davam por ambas as partes em disputa, ou seja, havia competição entre os que mais fraudavam. Portanto, afirmar peremptoriamente que as eleições no período, por abarcarem relações coronelísticas ou clientelísticas e por serem objeto de contínuas fraudes, eram favas contadas, implica em subestimar as clivagens interregionais e a existência de um mercado político com graus variados de competição.

Por outro lado, houve um investimento progressivo na coibição das fraudes por parte dos legisladores. São incontestáveis as dificuldades encontradas para que tais leis efetivamente pudessem ser cumpridas. A ausência de uma Justiça Eleitoral aliada à alocação do controle dos processos eleitorais em dois poderes eleitos pelo povo, o Executivo e o Legislativo, constituíam-se em obstáculos significativos a evitar que a vontade das urnas se fizesse valer. O que se propõe não é a contestação da existência da fraude, mas a identificação de seu uso como parte do jogo político. Os atores que competiam pelo poder dela se valiam.

Em relação ao voto secreto, convém ressaltar que a Lei Eleitoral de 1892 o havia estabelecido. No entanto, uma inovação significativa foi introduzida por uma nova lei decretada em 1896: a instituição da possibilidade do voto a descoberto. "Será lícito a qualquer eleitor votar por voto a descoberto, não podendo a Mesa recusar-se a aceitá-lo." (Lei n. ${ }^{\circ} 426$, de 7 de dezembro de 1896, artigo $8^{\circ}$ ). Abria-se um novo precedente, antes não previsto: o direito individual de optar-se pelo voto aberto, tendo o eleitor, inclusive, a possibilidade de levar para casa uma cópia de seu voto depositado na urna. Embora tal prerrogativa tenha sido colocada como uma opção do eleitor, as conhecidas barganhas entre votos e favores poderiam, a partir daquele momento, ser autenticadas. O Decreto n..$^{\circ} 12.391$, de 1917, alterou novamente essa previsão, proibindo o voto a descoberto, a não ser em ocasiões em que o eleitor votasse em cartório.

Embora proibido, de alguma forma os eleitores continuavam a votar a descoberto. Não fosse isso, o que justificaria as campanhas pelo voto secreto nos anos 20? Conhecida sempre foi a distância entre o Brasil real e legal, desde tempos remotos. Para que o pacto coronelista de fato funcionasse, as lideranças locais teriam que ter o controle sobre o resultado das urnas. Um dos caminhos era conhecer a opção dos eleitores, seus clientes; outro, seria o controle sobre os processos eleitorais, que com a intervenção do Judiciário passou a ser cada vez menor.

Sem contestar a distância entre discurso jurídico e prática política, reconhecendo que apenas uma parcela minoritária participava dos processos eleitorais e admitindo que a fraude era um instrumento poderoso para a garantia de resultados eleitorais, ainda assim, é preciso destacar que o voto era disputado e possuía valor de legitimação de candidaturas; que os legisladores esforçavamse por punir e controlar as fraudes; que as eleições envolviam competição entre candidatos; e que por meio delas era possível promover a renovação das lideranças.

Apesar das dificuldades de se fazerem valer os preceitos da democracia liberal, os resultados eleitorais atestam que havia renovação da classe política a cada legislatura. Dados de Santos ${ }^{18}$ revelam que o regime republicano manteve

18 SANTOS, Wanderley G. dos. “O sistema oligárquico representativo da Primeira República”. Revista Dados, Rio de Janeiro, jan-mar, 2013. 
os mesmos índices de renovação do período imperial, que não era baixo, por representar cerca de $40 \%$ dos deputados. Atualmente, mesmo nas democracias de massa, essa taxa é bem semelhante. No Parlamento brasileiro, por exemplo, nas eleições de 2014, o índice de renovação foi de 43,7\%, bem próximo ao encontrado por Santos para a Primeira República, o que nos leva a concluir que as oposições tinham expectativa de chegar ao poder por meio do processo eleitoral, mesmo que viciado.

Desde as análises de Edmund Burke, em seu discurso aos eleitores de Bristol em 1774, é sabido que a delegação de poder conferida a um deputado pressupõe que ele possua certa margem de autonomia. Cabe a ele, como representante de seus eleitores, priorizar os interesses da nação sobre o dos indivíduos. Caso isso não ocorra, a única sanção possível por parte de seus eleitores é não o reeleger nas próximas eleições. ${ }^{19}$ Talvez a insatisfação dos representados explique, entre outras razões, o alto índice de renovação encontrado no Parlamento republicano.

O governo provisório que assumiu o poder após a Revolução de 1930 criou duas comissões para alterar as leis eleitorais em vigor. O Código Eleitoral que delas resultou em 1932 estabeleceu o escrutínio uninominal - rompendo com a longa tradição do voto em lista fechada - ao lado da representação proporcional (antes era maioria simples), que permanece até os dias de hoje. ${ }^{20}$

O referido código manteve a possibilidade das candidaturas avulsas, ou seja, sem vinculação a partidos políticos, o que já ocorria anteriormente. Tal possibilidade contribuiu para a imensa dispersão de nomes votados e para a fragilização do próprio sistema partidário brasileiro. O eleitor poderia votar em qualquer nome, mesmo que não fosse candidato e mesmo que não estivesse vinculado a um partido. Tal situação só seria alterada em 1945.

Mas, sem dúvida, a criação da Justiça Eleitoral foi o passo mais importante dado em direção a um controle maior das fraudes e à organização geral do sistema eleitoral. A sua criação decorreu de um decreto do governo provisório de n. ${ }^{\circ} 21.076$ (artigo $5^{\circ}$ ) com o fim de regular as eleições para a Assembleia Constituinte de 1934. Mas ela não teria sido criada não fosse o progressivo aumento da participação do Judiciário no processo desde os anos 10, até que se tornasse consensual entre os contemporâneos atribuir-se a um terceiro poder o controle sobre a renovação dos demais.

Convém ressaltar que a limitação do exercício de um direito político fundamental não impediu a participação política dos que não tinham direito ao voto. Ela se processaria através de mecanismos alternativos, a exemplo do associativismo, em suas diversas modalidades, como o mutualista, sindical, filantrópico, literário, científico, entre outros. Estudos recentes têm apontado para a significativa mobilização da sociedade civil brasileira no final dos oitocentos e primeiras décadas do século XX em contraposição a uma sociedade de indivíduos passivos. ${ }^{21}$ Ao mesmo tempo, a imprensa funcionava como canal de expressão de

19 PITKIN, Hanna F. “Representação: palavras, instituições e ideias”. Revista Lua Nova. São Paulo, n. 67, 2006.

20 PORTO. O voto no Brasil, p. 230.

21 Em relação ao associativismo sindical, entre os inúmeros trabalhos disponíveis, destacamos: GOMES, Ângela M. de C. A invenção do trabalhismo. Rio de Janeiro: luperj/Vértice, 1988; BATALHA, Cláudio. O movimento operário na primeira república. Rio de Janeiro: Zahar, 2000; DEMINICIS, Rafael B.; REIS FILHO, Daniel A. (orgs.). História do anarquismo no Brasil. Niterói e Rio de Janeiro: Ed. UFF e Ed. Mauad, 2006, v. 1. No que tange ao associativismo mutualista, uma coletânea recente reuniu os principais trabalhos sobre o tema: MAC CORD, Marcelo; BATALHA, Claudio H. M. (org.). Organizar e proteger: Trabalhadores, associações e mutualismo no Brasil (séculos XIX e XX). Campinas: Unicamp, 2014. Acerca dos demais associativismos, ver FONSECA, Vítor M. M. da. No gozo dos direitos civis: associativismo no Rio de Janeiro, 
interesses e de formação de opinião. Muitas vezes eram os jornais os únicos meios de intervenção das oposições sobre a política. Portanto, a liberdade de imprensa, mantida em quase todo o período, foi fundamental para que a defesa dos direitos tivesse lugar.

\section{A representação corporativa: uma ampliação da cidadania política?}

É sabido que a República, ao adotar o regime federalista não isonômico, trouxe para a cena política estados-atores, que passaram a disputar no Parlamento o controle sobre os rumos do novo regime. A hegemonia dos estados fragilizou o quadro partidário nacional. Uma multiplicidade de pequenas siglas foi criada, a maior parte delas de base local, a disputar parcelas do poder que se encontravam alocadas nos partidos regionais mais consolidados. Como os espaços para as minorias eram diminutos, tais siglas conseguiam, no máximo, eleger lideranças municipais ou prover capital político para alguns candidatos que, ao se tornarem mais conhecidos, poderiam ser chamados a compor a chapa dos grandes partidos regionais. ${ }^{22}$ Tal modelo institucional de representação de interesses estava longe de abarcar a maioria da população, sobretudo os trabalhadores. Ao longo de toda a Primeira República, o número de representantes dos interesses dos trabalhadores foi inexpressivo.

Angela Gomes ${ }^{23}$ destaca que somente na década de 1920 as associações operárias optaram por uma estratégia parlamentar, uma vez que a representação partidária era rejeitada tanto pelos anarquistas quanto pelos socialistas. Antes disso, apenas um representante dos interesses dos trabalhadores ocupara a vaga de deputado constituinte em 1890, José Augusto Vinhaes. Nos anos 20, Maurício de Lacerda e Azevedo Lima, que não eram operários, mas defendiam as causas trabalhistas, foram eleitos deputados; o primeiro pelo Bloco Operário Camponês. Portanto, pode-se afirmar que o estabelecimento da representação corporativa dos trabalhadores, proposta por Vargas em 1931, constituiu-se em significativo aumento da representação dos trabalhadores no Parlamento.

As discussões sobre a representação corporativa eram antigas no Brasil, ou seja, datavam da segunda metade dos oitocentos, mas não chegaram a compor nenhum código eleitoral. Alberto Torres, já na década de 1910, criticava o sistema representativo previsto pela Constituição de 1891 como sendo ineficaz e não adaptado à realidade brasileira. Seu livro "O Problema Nacional Brasileiro", ${ }^{24}$ publicado em 1914, já apontava para a inadequação da importação do formato liberal, que teria aprofundado as relações de poder local, características de nossa formação paternalista. Uma das soluções por ele apontadas seria a representação corporativa. Era ela a única capaz de eliminar os conflitos e auxiliar no processo de organização da sociedade por meio do trabalho, libertando o país do mando das oligarquias regionais. Seu modelo, no entanto, não conferia caráter deliberativo às corporações, apenas consultivo.

1903-1916. Rio de Janeiro: Faperj-Muiraquitã, 2008.

22 FIGUEIREDO, Vitor F. "Voto e competição política na Primeira República: o caso de Minas Gerais”. (Tese de doutorado. Programa de Pós-Graduação em História da UFJF, 2016).

23 GOMES. A invenção do trabalhismo, p. 29, 150 e 172.

24 TORRES, Alberto. O problema nacional brasileiro. $2^{\text {a }}$ ed. São Paulo: Ed. Nacional, 1933. 
Provavelmente por essa razão, Oliveira Vianna, cerca de vinte anos mais tarde, defenderia o mesmo modelo. Ele previa a existência de conselhos responsáveis por auxiliar o governo na tomada de decisões. É sabido que Vianna era um leitor e admirador de Alberto Torres. Ao fim da década de 20, falava sobre a necessidade de se rever o sistema representativo brasileiro, como forma de superar o "insolidarismo" que nos caracterizava, por meio da abolição dos partidos políticos e da participação das classes organizadas nos negócios públicos. ${ }^{25}$

Outros teóricos autoritários dos anos 30 defendiam a proposta corporativista, o que se tornou mais fácil depois das experiências francesa, portuguesa e espanhola, para além da italiana. Tanto Francisco Campos como Azevedo Amaral apostaram na representação profissional como um meio de resolver os problemas que eles viam no funcionamento dos parlamentos. Francisco Campos teve efetiva intervenção sobre os formatos de participação corporativa criados no Brasil antes, durante e depois do Estado Novo. ${ }^{26}$

Mas a onda corporativa não se limitou aos teóricos. Vargas, em seu primeiro discurso proferido sobre o tema, logo após a Revolução de 30, defenderia o modelo, como se pode observar por meio da citação abaixo:

[O programa da revolução] modifica o regime representativo, com a aplicação de leis eleitorais previdentes, extirpando as oligarquias políticas e estabelecendo, ainda, a representação por classes em vez do velho sistema da representação individual, tão falho como expressão da vontade popular. ${ }^{27}$ (grifos nossos).

Nesse mesmo ano, o decreto do governo provisório de número 19.770, de 19 de março de 1931, inaugurava a representação corporativa no Brasil. O mesmo decreto previa o controle estatal sobre o funcionamento dos sindicatos, que passariam a ser registrados no Ministério do Trabalho, Indústria e Comércio, além de terem que enviar relatórios anuais de suas atividades. Adicionalmente, funcionariam como órgãos colaboradores, com o fim de resolver eventuais conflitos de classe.

O Código Eleitoral de 32 previa que o governo convocasse os eleitores para a escolha de seus representantes na Assembleia Nacional Constituinte e estabeleceria "as condições de representação das associações profissionais", ou seja, ficava estabelecida, dois anos antes da nova Carta, a representação classista no Parlamento. Um novo decreto publicado em 5 de abril de 1933, com o número 22.621, definia os números da representação corporativa na Constituinte. Seriam 40 representantes profissionais em um universo de 254 deputados (15,74\%). O Decreto n. ${ }^{\circ} 22.653$, de 20 de abril de 1933, estabelecia a forma de escolha dos representantes corporativos. Seriam 40 profissionais, sendo 20 representantes dos empregadores e 20 dos empregados.

Dessa forma, se compôs uma representação corporativa na Assembleia de 34. Ela comporia $1 / 5$ do Parlamento e seria dividida em cinco grupos de deputados, a saber: 1) Lavoura e pecuária; 2) Indústria; 3) Comércio e transporte; 4) Profissões liberais; e 5) Funcionários públicos.

25 OLIVEIRA VIANNA, F. J. Problemas de política objetiva. São Paulo: Nacional, 1930, p. 19.

26 SANTOS, Rogério D. "Ditadura e corporativismo na Constituição de 1937: o projeto centralizador e antiliberal de Francisco Campos”. In: PINTO, António; MARTINHO, Francisco P. (orgs.) A onda corporativa: corporativismo e ditaduras na Europa e na América Latina. Rio de Janeiro: Ed. FGV, 2016.

27 Discurso proferido em 2 de janeiro de 1931 em um banquete das Forças Armadas. VARGAS, Getúlio. A nova política do Brasil. Rio de Janeiro: J. Olympio, 1938. 
A Constituição de 1934 alterou o modelo de representação profissional proposto por ocasião da eleição para a Assembleia. O número de representantes foi ampliado de 40 para 50 membros. Ao invés de quatro categorias genéricas (empregados, empregadores, funcionários públicos e profissionais liberais), passou-se a ter cinco categorias. E dentro de cada uma delas, à exceção dos profissionais liberais, haveria representantes dos empregadores e dos empregados.

Interessante destacar que, além de Vargas, o Clube Três de Outubro também havia se manifestado publicamente a favor da representação corporativa, embora sem consenso interno. A ausência de acordo em torno de um modelo tão inovador e controverso esteve presente também na própria comissão do Itamaraty, responsável pela elaboração de um pré-projeto constitucional. Seus membros não conseguiram chegar a um consenso em relação ao modelo.

Como se vê, a ideia era polêmica e os modelos disponíveis variáveis. A proposta não foi aprovada sem oposição na Constituinte. Havia um grupo de personagens destacados do mundo jurídico e literário que a ela se opunham como Gilberto Amado, José Maria Belo e Odilon Braga, este último, ativo partícipe da Revolução de 30, ao lado de Vargas.

A proposta alternativa não chegava a excluir de todo o modelo, o que demonstra a existência de uma aceitação generalizada das experiências em curso em outros países. Ela previa o estabelecimento de conselhos técnicos que assessorassem o Congresso na proposição de toda e qualquer legislação. Tais conselhos teriam poderes significativos, na medida em que a eles caberia impedir ou demandar a apreciação de projetos pelo Parlamento.

Como se percebe, mesmo a oposição propunha alternativas de representação corporativa mais flexíveis, porém, ainda corporativas, embora não abrisse mão de defender o Parlamento como locus de defesa dos interesses representativos dos indivíduos e não das categorias profissionais. Importante destacar que tal proposta teve apoio de parte da representação dos trabalhadores na Assembleia que compunha uma "minoria proletária" formada por quatro deputados classistas. ${ }^{28}$

As proposições corporativas derivavam de uma avaliação generalizada acerca da insuficiência do Parlamento como locus de deliberação política. Os empresários postulavam pela criação de conselhos com funções consultivas, capazes de conferir à gestão pública um saber técnico que, de alguma forma, compensasse as fragilidades de um Parlamento pouco qualificado. Tal visão ia ao encontro das ponderações de Oliveira Vianna, que não achava que as organizações da sociedade civil brasileira estivessem aptas para o exercício de funções parlamentares. O caráter meramente consultivo dos conselhos foi inserido na Constituição estadonovista, embora nunca tivesse sido colocada em funcionamento.

Costa Porto 29 afirma que um dos motivos que levaram Vargas a defender a representação profissional foi a intenção de fragilizar a presença de alguns estados hegemônicos, que com suas grandes bancadas conseguiam reverter facilmente decisões do Executivo. Como ele teria possibilidade de interferir sobre a composição da representação dos trabalhadores, seria possível reduzir o peso de algumas bancadas mais numerosas. Em levantamento realizado por Ângela Gomes ${ }^{30} \mathrm{da}$ representação profissional por estado, é possível confirmar a afirmação de Porto.

28 GOMES. A invenção do trabalhismo, p. 181.

29 PORTO. O voto no Brasil, p. 250.

30 GOMES, Ângela de Castro et al. (coord.). Regionalismo e centralização política. Rio de Janeiro: Nova Fronteira, 1980, p. 449. 
A representação patronal esteve concentrada em cinco grandes estados, quase os mesmos que controlavam na Primeira República cerca de 70\% do Parlamento: DF, SP, MG, RS e PE. Já a dos trabalhadores provinha de 12 estados diferentes, tendo a sua representação melhor distribuída entre as unidades federadas. Os objetivos de Vargas haviam sido atingidos.

\section{Considerações finais}

Bendix ${ }^{31}$ afirma que a expansão da cidadania é proporcional à ampliação do Estado, ou seja, para que os direitos previstos sejam de fato usufruídos pelos cidadãos, torna-se necessário que o Estado seja amplo o suficiente para garantir o exercício dos mesmos. A ampliação do Estado, que acompanha a extensão dos direitos, é própria dos períodos de modernização. Dessa forma, modernizar-se significa, ao mesmo tempo, vivenciar os processos de industrialização e urbanização, ambos em curso no Brasil durante as décadas de 1920 e 1930. Nesse período, não só a cidadania era limitada como o Estado era mínimo.

Entre os três poderes da República, certamente o Judiciário era o menor deles, o menos aparelhado ao desenvolvimento de suas funções. A reforma constitucional de 1926 conferiu-lhe uma melhor estrutura. A atribuição do controle dos processos eleitorais a um braço específico do Judiciário, como a Justiça Eleitoral, foi expressão dessa ampliação e da garantia do exercício dos direitos políticos e da representação institucional de interesses.

Bendix igualmente afirma que os projetos de cidadania surgiram em ambientes completamente adversos, ou seja, em locais onde as circunstâncias não os teriam engendrado naturalmente, chocando-se com as tradições em curso, no que se aproxima das análises de Tavolaro, para o qual dentro de um mesmo país, coexistem modernidades múltiplas a gerar graus diversos de usufruto dos direitos. Em centros mais urbanizados e mais industrializados, o acesso aos direitos, sejam eles civis, políticos ou sociais, é bem maior que nas áreas rurais ou nas cidades do interior do país. Em grande parte, essa ausência de direitos se deve à ausência do Estado. Ou seja, ocorreu a formalização legal do direito sem que houvesse capacidade real do Estado em garanti-lo, gerando uma situação peculiar, distante em relação ao "tipo ideal", mas que não pode ser tomada como um desvio ou uma insuficiência, apenas como uma particularidade. E tal como afirmou Tilly, foi relevante o papel do Estado na ampliação desses direitos, embora não se possa descartar a luta de variados setores sociais organizados para esse fim.

A previsão de direitos políticos nas duas primeiras constituições republicanas e as alterações das regras de representação apontam para a ampliação da cidadania política ao longo do período, sobretudo para aqueles que dela estavam excluídos, como as mulheres, os trabalhadores e os indivíduos sem renda declarada. Cabe refletir até que ponto a representação corporativa de fato funcionou como um instrumento valioso nas mãos dos trabalhadores em benefício de seus representados, ou, como aponta Pitkin, possa ter funcionado em atenção a meros interesses individuais, em detrimento do bem público. ${ }^{32}$ Embora a experiência tenha sido curta, uma análise mais aprofundada sobre o papel de tais grupos e seus interesses está por ser realizada.

31 BENDIX, R. Construção Nacional e Cidadania. São Paulo: EDUSP, 1996.

32 PITKIN. "Representação", p. 28 e seguintes. 
Mas sabemos que tais avanços foram interrompidos três anos depois, transformando a vigência da Carta de 1934 na mais breve de nossa história. O que só comprova a tese da provisoriedade dos direitos, sempre em disputa por diferentes grupos de interesse.

Procuramos acompanhar as mudanças dos direitos políticos e dos mecanismos de representação da sociedade civil no Parlamento por meio de uma análise transversal que perpassava as "duas repúblicas". Percebemos que o sistema eleitoral foi sendo aprimorado, com o fim de fazer valer a vontade das urnas, por meio do combate às fraudes. A ampliação do corpo de eleitores permitiu que um maior número de pessoas usufruísse do mais importante dos direitos políticos, o de voto. Mas também observamos que o peso do estabelecimento do voto feminino sobre o conjunto dos eleitores foi muito pequeno. Vimos que a representação corporativa, que vinha sendo discutida desde a década de 1910, ganhou força nos anos 30, muito por influência do contexto internacional do entreguerras. O quadro partidário brasileiro, já desde a implantação da república muito fragilizado, manteve-se pouco estruturado nos anos seguintes. Durante todo o período, os partidos permaneceram regionalizados, não tendo se formado um sistema partidário nacional. A representação corporativa contribuiria também para o seu esvaziamento.

Por outro lado, o crescente envolvimento dos trabalhadores nos processos de decision making culminou com o incentivo à sindicalização e à representação profissional no Parlamento. Não obstante a perda de autonomia de algumas agremiações por meio da intervenção estatal sobre elas, a nova janela de oportunidades que se abriu aos trabalhadores contribuiu para o acúmulo de experiência, o desenvolvimento de novas habilidades e realçou a importância da luta político-partidária como uma das mais importantes estratégias de obtenção de direitos. Do patamar que partiram ao fim do século XIX à representação formal no Congresso, há uma grande distância. Acreditamos que a sua superação tenha contribuído para fortalecer os anseios pela expansão de seus direitos de cidadania.

Recebido em 21/02/2018

Aprovado em 26/03/2018 